\title{
Deformation simulations of plastic parts with consideration of assembly constraints
}

\author{
Symulacje deformacji wyprasek \\ z uwzględnieniem utwierdzenia wynikającego z montażu
}

PRZEMYSŁAW POSZWA MAREK SZOSTAK *

DOI: https://doi.org/10.17814/mechanik.2017.12.204

\begin{abstract}
The paper deals with the influence of part assembly on deformation of plastic part produced with injection molding technology. Parts tend to deform because of non-uniform shrinkage, which can be predicted with CAE injection molding software. Calculations usually do not consider the application of the part. In this paper, several examples were used to present the influence of assembly on the shape of the part.
\end{abstract}

KEYWORDS: injection molding, deformation, assembly

Development of polymer materials processing allows for the production of increasingly complex, often thickwalled details. This trend is very strong, among others, in the automotive industry and household appliances.

Plastics are characterized by high shrinkage when passing from the liquid to solid phase. This causes significant problems with the dimensional accuracy of molded parts [1]. It would not be a problem if the contraction in the whole volume was uniform, but depending on the conditions (mainly temperature and pressure) the material retains a different specific volume. Differences in the specific volume in individual places result in an uneven contraction, which is the basis of deformation [2].

Shrinkage of the part is subject to compensation - the injection mold cavities produced are actually slightly larger, so that after shrinkage, the finished product has the expected dimensions [3]. The problem, however, is that due to the uneven contraction, the prediction of optimal compensation is practically impossible, especially in the case of complex geometries, where there is also a large heterogeneity of the walls. Without the programs for simulating the plastic injection process, the size of the dimension compensation of the injection mold cavity cannot be optimally selected.

A characteristic feature of the automotive industry is the use of elements of considerable thickness or high ribbing and with narrow dimensional tolerance of both global (general shape deviation in terms of assumed geometry) and assembly (deviation of assembly dimensions, e.g. spacing of mounting holes) [4-6]. This is due to the fact that plastics have lower rigidity, and the

\footnotetext{
* Mgr inż. Przemysław Poszwa (przemyslaw.b.poszwa@doctorate.put.poznan.pl), dr hab. inż. Marek Szostak (marek.szostak@put.poznan.pl) - Instytut Technologii Materiałów Politechniki Poznańskiej
}

constructors expect from the elements produced by the injection method, the accuracy not much worse than in the case of metal products [7].

\section{Measurement of deformation}

The measurement of deformation is a non-trivial matter. In industrial practice, it is limited to attempts to analyze the distribution of colors on the surface of the molding without taking into account aspects such as the coordinate system of the molding and the method of measuring warping.

The coordinate system of a part is a basic problem in the case of elements for the automotive industry, which are oriented in the whole vehicle coordinate system. Inadequate part orientation may result in an incorrect analysis result. This is particularly important for narrow tolerances, where a certain inconsistency between the axis orientation causes that the determined deformation will be acceptable, although in reality, it will go beyond the acceptable range (for given processing conditions). This effect is presented in fig. 1, where the same part was turned by $45^{\circ}$ and measured along an axis that initially coincides with one of the sides.

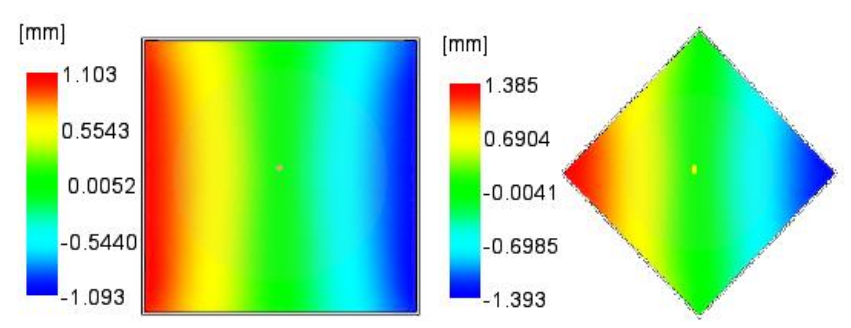

Fig. 1. Measurement of deformation of the part by the best fit method for two different coordinate system settings

Another aspect is the method of distortions measuring. By default, simulation programs (e.g., Autodesk Moldflow) use the best fit method as the basic analysis of warpage. It depends on choosing the arrangement of the molding so that the average difference between the base position (according to the CAD model) and the obtained one (deformed part) is as small as possible. In the case of a flat square plate presented in fig. 1, the dimension changed by $1.1 \mathrm{~mm}$ and by $-1.1 \mathrm{~mm}$. For a simple part, a simple conversion can be made to obtain a real change in a given linear dimension. This is not possible for more complicated moldings. 
In addition to the best fit method, specific measuring planes are used, determined using the so-called anchors. At the point of the first anchor, the base model and the deformed part are restrained. The introduction of two additional points allows to determine the plane, against which deformations will be measured. This is very important, because in most cases, it is only the correct definition of the measurement planes that allows to analyze the form of deformation of the moldings.

Fig.2 presents the board from fig. 1. The beginning of the system was placed in one of the corners. The negative value of the measurement results from the fact that due to the contraction the part has been reduced.

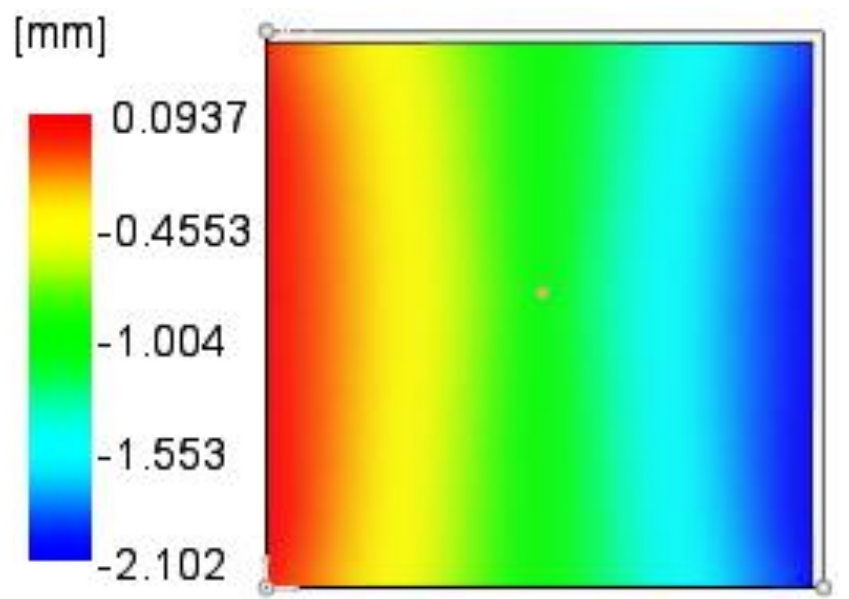

Fig. 2. Measurement of deformation using anchors

The injection simulation software also allows to select the optimal compensation of the forming cavity. On the basis of this analysis, information is obtained as to how much the socket should be scaled in individual directions to obtain the minimum strains measured by the best fit method. In the situation presented in fig. 1, the compensation amount was respectively: 1.964\% (along the horizontal side), $1.962 \%$ (along the vertical side) and $1.904 \%$ (on the thickness) in the left variant and respectively: $2.126 \%, 2.145 \%$ (along the sides) and $1.904 \%$ (on the thickness) in the right variant. In industrial practice, isotropic compensation is used, but incorrect reading of the compensation value (with wrong orientation of the coordinate system) will affect the final product.

Another way of analyzing deformation of molded parts is to measure the position of individual characteristic points (e.g. centers of mounting holes, points located on the edges). In the case of this type of size, a more advantageous solution is to measure a given dimension after deformation for various compensations. Knowing that the position of individual points can be displaced due to uneven contraction, their position for various compensations should be checked to select the compensation amount, for which all holes meet the tolerances.

\section{Assembly and deformation analysis}

In this paper, it was decided to discuss the impact of assembly on deformation of moldings. Many plastic elements, especially those with complex geometry, are installed in various types of devices (appliances, cars).
They are expected not only to be easy to assemble, but also to meet the appropriate shape tolerances.

The assembly process causes additional deformation of the parts. These deformations arise as a result of fixing the molding in particular places (e.g. holes). If restraint occurs in more than one place, it is impossible to obtain information about the actual deformation with the aforementioned tools, because they are only able to set the anchor in the place of restraint. Similarly, it is impossible to determine the change in linear dimensions - it may turn out that after mounting the part in two places, the third place will be impossible to fix.

The results of simulations carried out in Autodesk Moldflow Insight 2017 for three elements are presented below:

- C-shaped moldings (P1),

- moldings with three holes $(P 2)$,

- car interior element (P3).

The first two fittings were simulated using a midplane mesh (surface, $5 \mathrm{~mm}$ thick), and the last - 3D mesh. The material used was Moplen HP500N. In the case of $P 1$ and $P 2$, a simplified cooling system with low efficiency was designed to obtain significant deformations. The $P 3$ analysis did not take into account the effect of cooling system on deformation (a constant temperature was assumed on the surface of the entire forming cavity).

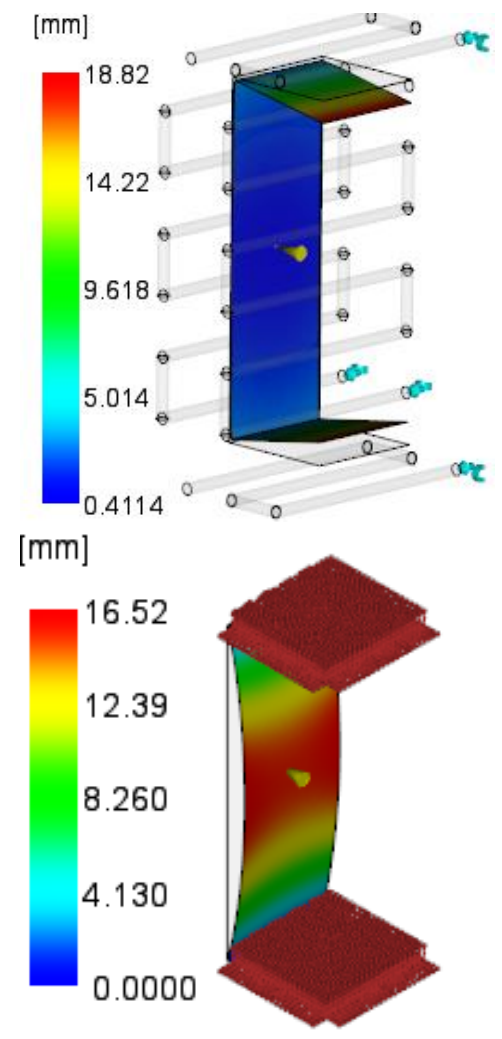

Fig. 3. Deformation of the $P 1$ part due to uneven shrinkage: a) without restraint with the marked cooling system, b) with restraint on the side walls

Analysis of the $P 1$ fitting (fig. 3) shows that in the absence of stiffening, relatively large deformations appear (the detail itself is $300 \mathrm{~mm}$ long). The fixing of the part causes (due to the high rigidity of the corner) the central part bends into the arch. In the example, large deformations occurred, however, even at 10 times smaller deformations, deflection at the level of $1 \mathrm{~mm}$ would be visible if the part was mounted. The inclusion of 
the assembly in the analysis allows predicting possible problems with the fitting of the joining parts.

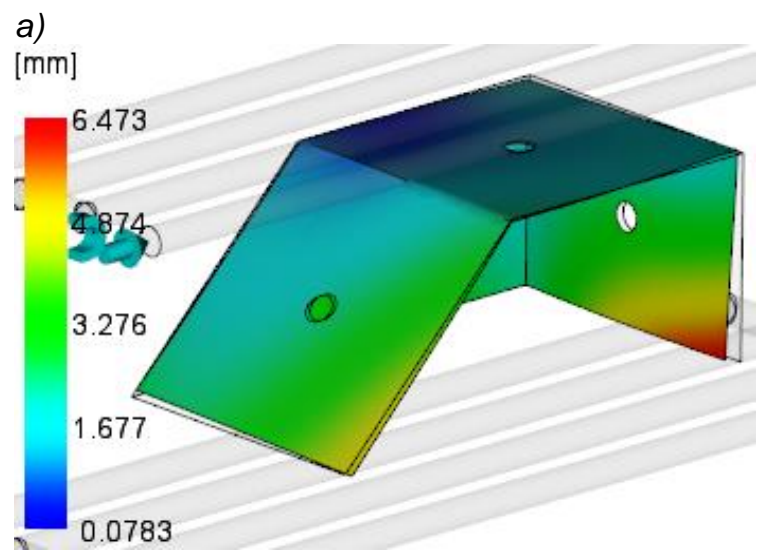

b)

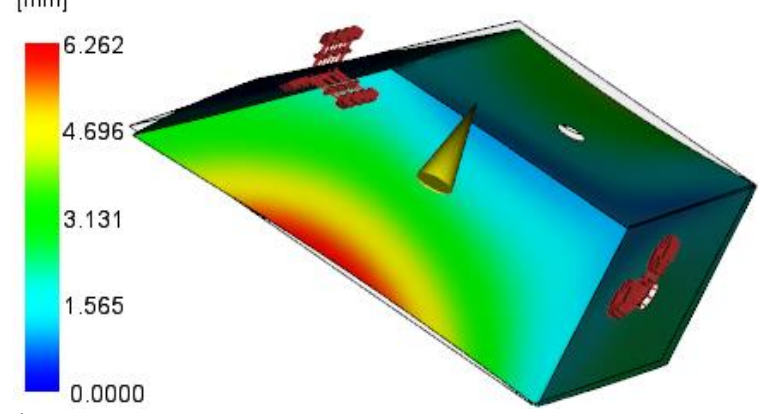

c)

[mm]

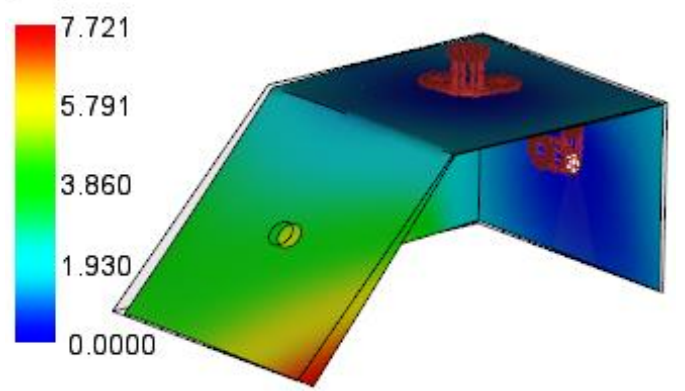

Fig. 4. The $P 2$ part deformation due to uneven contraction: a) without restraint, b) with restraint on an inclined and vertical wall, c) with restraint on a horizontal and vertical wall. Fig. 4a presents the geometry of the cooling system, and fig. $4 \mathrm{~b}$ location of the injection point

TABLE. Displacement of an unmounted hole due to uneven contraction of the part $P 2$, in $\mathrm{mm}$

\begin{tabular}{|c|c|c|}
\hline $\begin{array}{l}\text { Localization of } \\
\text { the hole tested }\end{array}$ & $\begin{array}{c}\text { No compensa- } \\
\text { tion } \\
\end{array}$ & $\begin{array}{c}\text { Automatic } \\
\text { compensation }\end{array}$ \\
\hline $\begin{array}{c}P 2.1 \text { - horizontal } \\
\text { wall }\end{array}$ & 1,16 & 0,87 \\
\hline $\begin{array}{c}P 2.2 \text { - horizontal } \\
\text { wall }\end{array}$ & 2,94 & 2,39 \\
\hline $\begin{array}{c}P 2.2-\text { inclined } \\
\text { wall }\end{array}$ & 2,3 & 1,11 \\
\hline $\begin{array}{c}P 2.3 \text { - inclined } \\
\text { wall }\end{array}$ & 3,65 & 1,71 \\
\hline
\end{tabular}

The $P 2$ part (fig. 4 ) is an element with three holes. The change in their position was investigated depending on the placement of anchors. In the first variant, anchors were not used $(P 2.1)$, in the second variant the anchors were placed on a vertical and inclined wall (P2.2), and in the third - on a vertical and horizontal wall (P2.3).

The Table shows the displacement of an unapproved hole depending on the mounting. To reduce deformation, automatic compensation was used in individual variants. The Table shows that the method (order) of assembly affects the size of the deviations of the shape, which in the analyzed cases are greater than in the case of the freeform. This may prevent proper assembly of the parts due to too large displacement of the opening or the fastening element.

The use of compensation reduces the deformation, however, the compensation value varies significantly depending on the method of fixing the part (the same effect was observed in the case of element $P 3$ ). For this reason, it is important to take into account the effect of assembly on these tolerances with narrow dimensional tolerances and a large number of tolerable dimensions.

a)

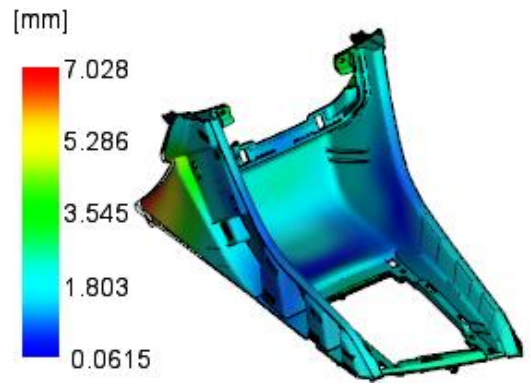

b)

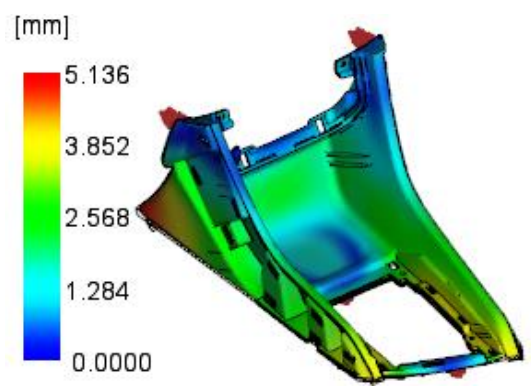

c)

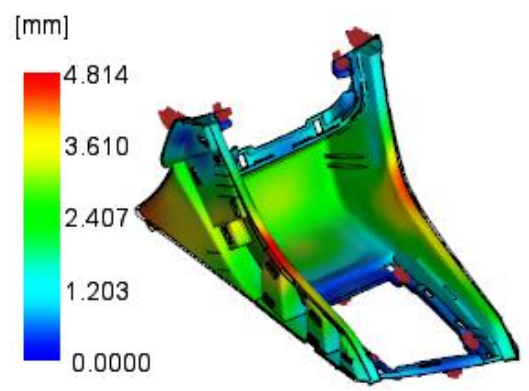

Fig. 5. Deformation of the $P 3$ part due to uneven shrinkage: a) without restraint, b) with restraint in the fastening elements, c) with restraint on the fastening elements and in the holes

The $P 3$ part (fig. 5) is an element of the car interior. It is a thick-walled mold with a large number of restraints. The biggest deformations appear when there is no restraint and are mainly in the back, not visible part. Virtually zero strains are observed in turn in the central, most visible part (these are analyzes using the best fit method). The introduction of restraints (fig. 5b) caused significant deformations in the area of vertical edges, which may hinder the interior fit of the car. Additional restraint in place of the holes causes (fig. $5 \mathrm{c}$ ) that the 
greatest deformations will occur in the most visible places and will also prevent proper fitting of the car interior. Reducing the deformation would be possible by locally reducing the rigidity of the part or changing the assembly method so that no such deformations could occur during this process.

\section{Conclusions}

Assembly of the parts is an issue omitted in the repetitive analysis of the deformation of the part. However, it is crucial at the stage of actual application of a given part. In the case of complicated elements, it is impossible to predict changes in shape due to uneven shrinkage, not to mention the influence of restraint.

It has been shown that fixing the molding in two places can cause great difficulty in fixing the next places. The assembly can also negatively affect the fit of the housing parts that must overlap a certain length.

The role of the assembly should be taken into account in analyzes, in which relatively large deformations of the moldings are observed. Poor selection of assembly sites may cause excessive deformation of the part in key regions and lead to difficulties with mounting parts or fitting enclosures, especially with narrow tolerances.

The solution to the problem is also to reduce the rigidity of the element so that the deformation of one fragment of the part does not cause deformation of the other parts. In the case of $P 1$, reducing the rigidity of the edges, e.g. by cutting, would result in significantly less deflection of the central part.

\section{REFERENCES}

1. Greener J., Wimberger-Friedl R. "Precision Injection Molding - Process, Materials, and Applications". Munich: Hanser Publishers, 2006.

2. Autodesk Inc. "Autodesk Moldflow Insight". San Rafael, CA. 94903, USA, 2017.

3. Fisher J.M. „Handbook of molded part shrinkage and warpage." Norwich, USA: Plastic Design Library, William Andrew Inc. 2003.

4. Sharma H., Janiwarad R., Heerkens R., Uikey D., Terragni M., Kulkarni A. "Automotive glazing - Polymeric systems providing enhanced design freedom and functionality". Annual Technical Conference of the Society of Plastics Engineers. 2016, pages 171-179.

5. Sethuraman K., Palanisamy K. "Material characterization of injection molded thermoplastic materials for finite element analysis - practical challenges". 2013 International Conference on Smart Structures \& Systems. Chennai, India, 2013, pages $47-52$.

6. Meng Z., Guo W., Wei X. „Comparative analysis of automotive interior trim materials based on Moldflow". Applied Mechanics and Materials. 117-119 (2012): doi:10.4028/www.scientific.net/AMM.117-119.1496, pages 1496-1500.

7. Zawistowski H. „Racjonalność tolerancji wymiarów i pasowań w dokumentacji wyrobów wtryskiwanych". Mechanik. 85, 4 (2012): pages 330-335. 